\title{
Policy and Practice Pathways to Addressing Menstrual Stigma and Discrimination
}

\author{
Archana Patkar
}

\section{INTRODUCTION}

I vividly remember being shushed at any mention of menstruation as a potential factor in absenteeism and poor learning achievements among adolescent girls in school in India. As recently as 1994, menstruation was the ultimate unmentionable, shrouded in multiple veils of forbidden sexuality and silent patriarchy. It did not help that there were no national policies that included menstruation, and none of the international human rights instruments explicitly mentioned it (Winkler and Roaf 2014). Working on education, adolescent health, and water and sanitation, I was struck by the systematic neglect of the human life course in the design of the built-up environment and seized every opportunity to understand and address menstrual stigma in policy and practice.

People at home, school, in the fields, offices, while traveling or playing a sport all ached with silent resentment at the ignominy of the monthly period because they were forced to suffer it in shame and silence. Adolescent girls were often uninformed and unprepared for menarche. Exclusion and shame led to misconceptions and unhygienic practices during menstruation (Chandra-Mouli and Patel 2017). The pattern repeated itself when conversations expanded to include persons with disabilities or HIV; those who had been genitally cut or who suffered from fistula; or those negotiating questions of gender and sexual identity. Discussing menstrual flows with the transgender community revealed a complex web of intersecting stigma around identity, occupation, class, age, caste, and ethnicity. With every conversation I engaged in, people of all ages poured out their thoughts, ideas, fears, hopes, and demands around menstruation. 
It was evident early on that, freed of stigma and mysticism, menstruation and its practical challenges might actually be nonthreatening and universal enough to stride across geographical context and sector silos as a powerful, positive disruptor for gender equality. Engineers, administrators, medical practitioners, nurse-midwives, hygiene promoters, educators, adolescent girls and boys, women and men from all walks of life and at different stages of life shared, listened, learned, and took a pledge to break the silence and walk without shame. Across national boundaries, from village, ward, county, province, and state, these voices rose to a crescendo that could not be ignored.

This chapter seeks to share a transformative policy pathway to gender equality using noncontroversial and pragmatic yet universal entry points, such as water, sanitation, and hygiene (WASH), to make explicit women's silent and neglected needs around menarche and menstruation. It draws on my professional experiences: first, from 1994 to 2010, as an independent adviser on education, health, WASH, and urban poverty projects to many governments and development partners; then, from 2010 to 2018 , as head of policy at the Water Supply and Sanitation Collaborative Council (WSSCC), a small organization within the United Nations working on sanitation and hygiene, with national governments in Asia and Africa.

The approaches employed in this work included a judicious mix of advocacy related to policy, systems behavior change, and the media (see Naeve et al. 2017). They often operated simultaneously and at different levels to build critical mass and reach tipping points for change. The process relied on making the voices of thousands of women and girls in Asia and Africa heard. These voices rang clear and true; they changed the perceptions, understanding, attitudes, and openness of diverse populations and their policy makers, who cast away age-old taboos to ask questions, learn, and embrace the universal truth of menstruation.

As a result, between December 2013 and 2019, India and Senegal published and Kenya approved menstrual hygiene/health policies and guidelines that broke the silence on menstruation and recognized menstruators' needs for basic services. Afghanistan, Bangladesh, Bhutan, Cameroon, Maldives, Nepal, Niger, Sri Lanka, and Tanzania followed suit, initiating trainings and institutional changes to health, education, and WASH government guidelines, budgets, and projects. A corpus of facilitators ${ }^{1}$ trained in gender equality and menstrual hygiene management (MHM), built a cadre of government officers who championed a carefully thought-through policy advocacy and practice agenda.

\section{Sanitation and Hygiene Are Powerful Entry Points for Change}

The language of WASH has long been one of taps, toilets, and soap, with people absent from the conversation. The recognition of the right to water and sanitation in 2010 (UNGA 2010) and the subsequent distinction and 
separation of the right to sanitation in 2015 were crucial milestones to move the sector forward (UNGA 2015; Winkler 2016). However, there remains a wide gulf between the rudimentary sanitation infrastructure available to those living in poverty and the obligations enshrined in these rights (Patkar 2016).

Far from being a pleasant experience, toilets, hand-washing facilities, and water points are often wet, damp, ill-smelling, dimly lit, unhygienic spaces where one can slip, fall, hurt oneself, or fall ill. Worse, sanitation services are heavily gendered, and women across the world report a fear of being followed, seen, touched, or violated (Kulkarni, Bhat, and O'Reilly 2017). Several studies have shown the intimate connection between the sanitation environment and the physical and mental well-being of women and girls (O'Reilly 2016; Sahoo et al. 2015). Furthermore, trans men and women feel unwelcome in single-sex toilets worldwide and are at risk of violence in these spaces (Boyce et al. 2018).

Urination, defecation, bathing, changing, and washing are basic, everyday needs that require privacy, comfort, and dignity. Women's and girls' sanitation behaviors are more expansive than urination and defecation (Sahoo et al. 2015), but these are often overlooked in policy, investments, and initiatives (WaterAid 2013). There has been surprisingly little analysis when it comes to the question of whether toilet access, design, or programs satisfy female needs around menstruation, menopause, and infant or elder care (Burt, Nelson, and Ray 2016). More generally, Phadke, Khan, and Ranade (2011) present a powerful reflection of women's experiences, encounters, and negotiations in urban public spaces in India. They eloquently illustrate that public spacesstreets, parks, playing fields, and courts-have been designed without women in mind and are therefore primarily frequented by men, excluding women and restricting their presence, visibility, and voices.

But it is just as possible to imagine a reversal of these gendered environments. Reimagine, if you will, public spaces redesigned to accommodate women and men of all ages, including menstruators, pregnant women, elderly persons, and caregivers with babies or young children. Imagine spaces where menstruators are able to change their menstrual materials, wash their cloths freely without being ashamed or ridiculed, dry them in the sun, and inhabit public spaces with confidence because they are sure of finding facilities to wash and change wherever they go. Imagine the breaking down of unconscious biases so that one day we can think of unisex washrooms that all genders can use without fear.

This simple yet inclusive reimagining of the world around us provided the underlying principles for the policy and practice change I sought. Because sanitation and hygiene require spaces that come with a certain conceptualization of use, toilets, washbasins, and their surroundings have the potential to help us think differently about human needs. There is something about the very basic human need to relieve oneself that is indisputably universal. Basic sanitation cuts across context, culture, and religion, and it remains a human need throughout life, with a significant daily impact on people's lives (Essity 2017a). 


\section{Proof of Concept: From Listening to Policy Development}

\section{Embarking on the Journey}

The journey began in India in 1994, when I worked with the state government on the District Primary Education Programme of Madhya Pradesh. The program was launched to achieve the objective of universalization of primary education. In the 1990s, Madhya Pradesh was a state plagued with a deteriorating male-to-female ratio, high maternal mortality, large gender gaps in education, and poor female participation in the workforce (Prabhu, Rampal, and Shukla 1995). Endowed with visionary leadership in the Ministries of Education and Finance, ${ }^{2}$ the powerful combination of human and financial resources and political will, positioned Madhya Pradesh to be a flagship state for achieving parity in primary education.

Madhya Pradesh was not alone in grappling with girls' frequent absenteeism, low motivation, and eventual dropping out of school. The links with menarche were unmistakable: restricted interaction, play, and mobility; reduced confidence; withdrawal and other behavioral changes; and low motivation to continue secondary school (Sommer et al. 2016). In my own state of Maharashtra, I witnessed first-hand the immense water and sanitation burden that women and girls experienced every day as water collectors, carriers, managers, and household and street cleaners. Sanitation duties were reserved for women and 'lower-caste' men, bringing with them distaste, discrimination, and exclusion. Menstrual blood - the mere mention of it-triggered the same reactions (see Sukumar [Chapter 13] in this volume). No one wanted to talk about it. Menstruation was socially, politically, and culturally unmentionable. Anyone articulating it was politely ignored. This complete denial meant that parents and teachers alike could not show interest in the topic. The 'menstrual lag' was systematic and seemed to persist even in schools with decent infrastructure. Teachers simply skipped over the reproductive health chapter or asked students to read it at home (Singh 2019). The human body and how it reproduced was a mystery to be magically unlocked once a couple tied the knot. Concepts of sexual attraction were entirely absent from the conversation, as was the link to reproductive anatomy and function (Thirunavukarasu and Simkiss 2013).

I came up against the same silence, reticence, and opposition when seeking answers in other sectors. Specialists in reproductive health, life skills, and WASH had never really thought about menstrual health (Bharadwaj and Patkar 2004). Privately, policy makers acknowledged that the issue 'may' be important but complained about the lack of data, social mores, and worries about 'corrupting' our girls if we talk about 'it'- 'it' being closely related to sexuality. While everyone I spoke to agreed in principle, ${ }^{3}$ many enlightened health and WASH professionals at the time simply felt that there were so many other important issues, this one could wait (Bharadwaj and Patkar 2004). 
But women could wait no longer. They wanted to talk about menstruation. They wanted to learn about their bodies. They wanted to have information and make choices. In focus group after focus group over the next ten years across India, and later in Cambodia, Senegal, Kenya, Niger, Nigeria, Tanzania, Bangladesh, Bhutan, Nepal, and Sri Lanka, women and girls opened up after the initial silence and embarrassment. Young girls and older married women alike, bombarded us with questions that they had never been allowed to ask. So did men and boys.

\section{Listening: The Menstrual Hygiene Management Lab}

The Nirmal Bharat Yatra, also called the Great WASH Yatra, a traveling carnival organized by the Government of India in partnership with WASH United, was a golden opportunity to make this silent demand heard (Desai 2012; Chanam 2012; Fernandez 2012). Conceived originally to deliver two important messages - stop defecating in the open and wash your hands at critical times with soap and water-we added a third: Manage your menstruation hygienically and with safety and dignity (Patkar 2012). This was a never-before-heard message in the government's health and WASH arsenal and a critical first step in breaking the silence. Neither cautious nor careful, it was broadcast with fanfare and the endorsement of Bollywood celebrities who talked about menstruation and sanitation in the same breath, with the blessings of the then-minister for Drinking Water and Sanitation, Jairam Ramesh (Gottipati 2012; YouTube 2012).

In 2012, a small team ${ }^{4}$ designed the Menstrual Hygiene Management Lab (MHM Lab) as part of the Great WASH Yatra that journeyed through five Indian states and $2000 \mathrm{~km}$ over 51 days (WaterAid, WSSCC, and Unilever 2013). Some 12,000 girls and women took part in focus group discussions, and the Yatra team collected preliminary data from 747 participants. Women, girls, men, and boys-everyone wanted to know about their bodies, learn to express and manage their secret fears and worries, feel clean, smell good, understand their sexual needs better, and be in control of their body and mind. The original MHM Lab design was conceived as a safe space for women, but we realized at our first stop, in Wardha, Maharashtra, that we had to include men and boys.

The questions did not stop at menstruation, as grandmothers, young men, and boys flocked to the MHM Lab to participate in focus groups and individual interviews conducted by our volunteers and partners. ${ }^{5}$ The results showed that $70.9 \%$ of the girls had no idea what was happening when they began to bleed and boys could not understand why girls suddenly stopped talking to them or playing with them (WaterAid, WSSCC, and Unilever 2013). All Lab participants, male and female, understood the menstrual cycle, made and wore a 28-bead sparkling saffron-and-red bracelet that represented the menstrual cycle and took the pledge to break the silence (Chanam 2012; George 2012). 
Thus, the MHM Lab served two interlinked objectives: It was a safe space to talk about menstruation at a time when this was still unthinkable and, it allowed us to build the evidence for policy change and refine the prototype training toolkit. The methodology of the MHM Lab was later refined and published as The MHM Lab Manual, endorsed by the Government of India as a training methodology for raising awareness and replacing stigma around menstruation with practical information and pride in one's own body (WSSCC 2013c). National, state, and district officials witnessed the evidence in action, which paved the way for policy reform.

\section{Evidence for Policy and Capacity Development}

The Union Minister, H.E. Jairam Ramesh, visited the MHM Lab and experienced first-hand the intensity of discussions and the massive queues before the tent (Gupta 2013). The news traveled quickly. Everywhere the Great Wash Yatra pitched its tents, the facilitators and managers of the MHM Lab met with state and district officials, principals, school teachers, and opinion leaders in addition to thousands of men, women, boys, and girls to talk about the issue and seek joint solutions to destroy the stigma and neglect that menstruators faced (Patkar and Deschaine 2014). This laid the groundwork for policy discussions at the state and national level.

Campaigns to build awareness and advocacy by powerful politicians and celebrities are important in initiating change. Certainly, they create a buzz, prod the media, and bring unmentionables to the agenda (Ma 2016). But as a long-term skeptic of advocacy's unfinished business and largely unmeasured effectiveness (see Puri 2016), I was determined to hitch the learning outcomes of the Yatra, impressive in terms of diversity and scale, to the readiness of the Ministry of Water and Sanitation to break the silence on menstruation in national policy.

On my next visit to the Ministry of Drinking Water and Sanitation in New Delhi in early 2013, Joint Secretary Jitendra Mathur, Directors Vijay Kumar and later Sujoy Mojumdar, and their colleagues were fully aware of the success of the MHM Lab. The conversation with the ministry moved rapidly: What would the integration of MHM into the national policy on water and sanitation look like? What were the budgetary implications? What capacity to implement change was needed, and how would this be built within the government system? How could the change on the ground be monitored for uptake, learning, and improvement?

Working with slim resources and the existing normative mandate of the Government of India, government partners and my team, we sought opportunities within existing government schemes to break the silence on menstruation. Putting together an amendment to the Nirmal Bharat Abhiyan (Total Sanitation Campaign) (Indian National Congress 2018) was a straightforward solution: Simple, easily understandable language that could immediately be translated into budgets and local plans across the country's 29 states, 725 
districts, and 7 union territories. The three paragraphs deliberately contained no human rights language and almost erred on the side of brevity. They simply stated that existing funds may be used "to raise awareness, information and skills on menstrual hygiene management" and to "implement safe disposal solutions for menstrual waste" (Ministry of Drinking Water and Sanitation 2013). The language used matched that of the existing water and sanitation policy and was therefore practical, output-oriented, and designed for use by planners and engineers. The aim was to get this off the ground-and it worked.

In September 2013 Pankaj Jain, the secretary in the Ministry of Drinking Water and Sanitation, Government of India, endorsed and launched the MHM toolkit at the first national MHM training for government officials from health, WASH, social welfare, and public administration held in New Delhi (WSSCC 2013a, 2013b, 2013c). Sixty-two participants from the states of Uttar Pradesh, Jharkhand, Bihar, Madhya Pradesh, Chhattisgarh, Uttarakhand, and Delhi attended the four-day training. The response was tremendous, resulting in demand and follow-up trainings in southern and western India.

In 2014, under the Modi government, menstrual hygiene was maintained under the national Clean India Mission (Swachh Bharat Mission) ${ }^{6}$ guidelines, which state, "Issues relating to women's personal hygiene namely menstrual hygiene are to be focused under the Swachh Bharat Mission (SBM). Girls and women have hygiene and sanitation needs linked to their menstrual cycle. Women suffer in the absence of knowledge about safe practices on Menstrual Hygiene Management (MHM)" (MDWS 2017). The guidelines provided funds to conduct information, education, and communication activities to raise awareness among all stakeholders about MHM, including why menstruation occurs and how to manage it safely (washing, cleaning, using, and changing clean absorbents regularly) and menstrual waste management (safe disposal solutions for used cloths and pads).

\section{Extrapolating a Pathway and a Methodology}

With MHM now firmly in national policy, a mammoth task lay ahead. Developing a pathway for menstrual health involved (1) deepening the engagement in India with a strategy to percolate the change holistically to local levels; (2) leveraging the momentum to expand menstrual health policy development to other countries and regions; (3) expanding the agenda to address other taboo topics; and (4) addressing the diversity of menstruators' needs.

\section{Deepening the Engagement in India}

Breaking the silence in policy was seen as a real victory by the ministry staff, who became passionate advocates for MHM. The language of the policy amendment was deliberately short and sharp, but it prioritized the first prong 
of increased information, education, and communication through sequencing of activities and funding. However, the tangible quickly takes precedence over slower, deep-rooted changes. The proxies that proliferated were menstrual absorbents, subsidies, handouts, unsustainable projects, and the endless rounds of training that poor women in communities often undergo to learn about their own stark realities. Despite the publication of MHM Guidelines with a focus on girls (MDWS 2015), MHM remained on the periphery of the Swachh Bharat Mission, whose primary aim was to make India open-defecation-free by October 2019 (MDWS 2018). As it became easier to talk about menstrual hygiene, sanitary pad distribution schemes became the flavor of the moment. Without complementary information, counseling, and support mechanisms in place, adolescent girls were unable to or chose not to use them (Chandra Sharma 2018). These schemes did little to change the narrative or to recognize and value the diverse experiences of menstruators across the life course. As Chris Bobel argues, "the largely product-based solutions that often follow fail to challenge the social construction of the menstrual body as dirty and in need of concealment" (2019).

The persistence of menstrual stigma points to the challenges of using the WASH sector, with its focus on hygiene and tangible solutions, as an entry point. Working with policy makers, it was prudent to couch activist actionsfor example, breaking the silence on menarche and menstruation-within the instrumentalist language linked to budgets and measurable outputs. The water and sanitation sector, ever pragmatic and action oriented, offered the ideal launch pad. However, without parallel mechanisms and advocacy stressing participation, voice, and choice, there was always a risk that change would be limited to physical design around taps and toilets, pads and cups. This would ignore the crucial need for reflection, spaces for dialogue, learning and sharing between men and women, and the myriad expressions of gender and sexual identity that are needed to replace body stigma and shame with knowledge and pride. MHM can too easily be co-opted by a training, pad-manufacturing, and distribution army, leaving notions of voice and agency far behind. Once the initial euphoria linked to a holistic approach dies down, champions leave and the dust settles, policies intended to be transformational are often narrowly interpreted. The menstrual hygiene movement seems to have settled on WASH facilities, tax-free pads, and incinerators as key indicators of action and success. Encompassing broader questions of menstrual health has thus far proved challenging in India, but the policy change can only be applauded as progressing a transformative agenda in a complex and diverse country of 1.4 billion people-a country in which the right to reproduction is traditionally seen as a family health and well-being issue (Kosgi et al. 2011) and menstruation, especially for young girls, means that marriage and childbirth are the next rites of passage into adulthood (CREA 2005). The developments to date are important early steps that have unleashed language, conversations, and demands that have been suppressed for centuries. And with them come a flurry of innovative strategies, resources, and programs to make up for lost time in India and beyond. 


\section{Broadening: Testing the Proof of Concept for Universality and Scale in Africa}

If senior, male government policy makers could talk about menstruation in the patriarchal states of Northern India, could the same be achieved in other geographies using the same methodology? Building on the success in India and momentum created at the international level through a series of advocacy events (ANEW 2013; Naafs and Brewer 2013), it was time to test the waters in Africa. In September 2013, a small team, ${ }^{7}$ in partnership with UNICEF WCARO in Dakar, Senegal, organized the first-ever multicountry training workshop on menstruation for government officers from 22 countries in West and Central Africa (ANEW 2013). Regional Sanitation Adviser for UNICEF WCARO, Jane Bevan, brought critical commitment and resources to break the silence in the region. We invited officers from health, education, WASH, and environment ministries, as well as teachers, trainers, practitioners, and activists. Participants shared personal stories of shame and stigma and forged a strong commitment, and the movement was born. Several meetings and discussions later, the Government of Senegal launched The Joint Programme on Gender, Sanitation and Hygiene, cofinanced by WSSCC and UN Women in Louga, Senegal, on March 8, 2014, to listen and respond to the needs of women and girls regarding sanitation and hygiene in policies, laws and regulations, and related budgets in Senegal, Niger, and Cameroon (see Aidara and Gassama Mbaye [Chapter 40] in this volume).

The policy pathway was similar to India and yet different. Senegal, with a population of 14 million, of which $60 \%$ were under age 25 , was rattled by the raw novelty of the term 'MHM.' From ward to village to ministry to agency, I was told that this would need to be handled extremely sensitively. However, a mix of essential ingredients - in this case, action research in urban and rural areas to fill the baseline and evidence gap, rapidly adapted tools following local interviews and focus groups, advocacy with parliamentarians and an interministerial committee-unleashed tremendous support for MHM (WSSCC and UN Women 2016).

Leading the charge were champions from the Health, Education, Environment, and $\mathrm{WASH}^{8}$ ministries, with the able support of the UN Women team in Dakar. ${ }^{9}$ For example, Amadou Diallo from the Ministry of Water and Sanitation in Senegal spoke eloquently about how the work on MHM had opened the eyes of the ministry to a new way of working-one that made complete sense within the ethos and culture of fairness, respect, and dignity innate in Senegalese tradition. MHM was able to weave a common thread across health, education, gender, environment, and WASHwithin government as well as development agencies-reflecting realities that are not confined to one sector and therefore must be solved through convergence. The Joint Programme has successfully integrated MHM in the national strategy of the Ministry of Water and Sanitation, which now mandates that investments in WASH take into consideration women's needs, particularly 
menstrual management (Ministère de l'Hydraulique et de l'Assainissement, République du Sénégal 2016).

English and Swahili-speaking Kenya presented an interesting contrast. In 2016, Kenya was already a hotbed of MHM activity, with large UN agencies and a plethora of national NGOs working on raising awareness and producing pads. However, it had yet to articulate a coherent approach to menstrual health and hygiene, as the focus was largely on keeping girls in school. Girls who had dropped out of school, HIV-positive women and girls, and female refugees were not yet a focus of the discussion (Geertz et al. 2016).

The first national MHM training was organized with the Ministry of Health in 2016 for 70 officers working in health, environment, water, and sanitation. It served to galvanize latent champions into action (Okwaro et al. 2016). 12 County first ladies were crowned MHM champions. An initially skeptical Ministry of Health was convinced about the relevance of the issue and the need to train all 47 counties and move to the logical next step: a coherent national policy. Building a cadre of trainers to work across East Africa was an important investment and critical link in the policy pathway. ${ }^{10}$

Kenya's - and the world's - first dedicated MHM policy, approved in November 2019, is a bold statement of recognition of its approximately 25 million menstruators and their needs. A series of multi-stakeholder consultations were convened by an impressive cast of characters: Director of Public Health Kepha Ombacho; his deputy, Jackson Muriithi; WASH Alliance and WSSCC national coordinator, Tobias Omufwoko; Knowledge and M\&E officer, Neville Okwaro from the Ministry of Health WASH Hub; and WSSCC. ${ }^{11}$ The meetings involved a range of NGOs, researchers, development partners, manufacturers, and county governments, and they were marked by numerous power plays: between national control and newly decentralized counties fighting for fiscal control; institutional fragmentation and confusion between which government authority would manage which aspect of MHM; competing interests on generating funds for particular pet projects or research; and lots of excitement around disposable and reusable pad innovation. However, the meetings were largely positive, with a shared desire for coherence in policy and practice. Translating the policy into meaningful budgets, actions, and monitoring across 47 districts is the next step, along with urgently needed product regulation, an area of concern for the Ministry of Health.

The Kenyan Cabinet, chaired by President Uhuru Kenyatta, approved the National Menstrual Hygiene Management (MHM) Policy highlighting MHM as a rights issue and bringing it into the mainstream of the country's health and development agenda (Government of Kenya 2019). The policy intends to highlight MHM as a rights issue and bring it into the mainstream of health and development. It examines the social, economic, cultural, and demographic context of MHM, including its implications for menstruators' health. Menstruation is a critical indicator of female health and vitality, and a healthy menstrual cycle indicates overall well-being. This policy aims to break the silence around the biological phenomenon of menstruation and menstrual blood to enable Kenya's 
women and girls to access information, make informed choices, and participate fully in all walks of life, every day of the month.

\section{Regional Declarations and Benchmarking}

Creating regional MHM hubs of activity on policy and practice was intended to engage neighbors, catalyze innovation and action, and break the silence on the ground and within WASH and health policy. The first countries chosen-India, Senegal, and Kenya-were also regionally recognized influencers, innovators, and leaders well placed to drive transformation beyond their borders. They then found regional counterparts for sharing, benchmarking, learning, and dialogue: Niger and Cameroon in West and Central Africa; Tanzania and Uganda in East Africa; and Afghanistan, Bangladesh, Bhutan, the Maldives, Nepal, Pakistan, and Sri Lanka in South Asia.

Regional sanitation conferences and their declarations were an essential part of this policy advocacy, as all countries report on their achievements regionally every two years (Naafs and Brewer 2013; Narayan et al. 2011). Bringing MHM into regional declarations was therefore crucial for advocacy, action, benchmarking, regional learning, and sharing. The fifth South Asian Conference on Sanitation (SACOSAN V) in Kathmandu, Nepal, in October 2013 ended with a declaration urging compliance measures on MHM facilities and explicitly calling for an end to discrimination across its eight member states (Kathmandu Declaration 2013). At SACOSAN VI in Dhaka, ministers and government officials from the Maldives, Sri Lanka, and Bhutan-as well as Sri Lanka's Minister of City Planning and Water Supply, Rauff Hakeem, and Member of the Legislative Assembly in India, Prem Lata Singhresponded to the concerns and demands expressed by adolescent girls, transgender persons, and persons with visual and hearing impairments. These were then reflected as commitments in the Dhaka Declaration (2016). Similarly, at AfricaSan V, Ministers Mansour Faye from Senegal and Wassalke Boukhari from Niger co-chaired a powerful session on MHM and spoke about their countries' commitments to breaking the taboo in policy and providing MHM-friendly public facilities and awareness programs (WSSCC and UN Women 2015a).

In addition, building capacity and equipping policy makers and practitioners with information and tools were essential. To deliver the SACOSAN commitments on MHM, WSSCC pledged to train government staff of key national ministries in all eight countries in the South Asian Association for Regional Cooperation (Theseira 2016). National trainings were complemented by regional trainings that brought together officials from several countries to listen, share, and learn in neighboring host countries (Okwaro and Davis 2017; Theseira 2016). Expanding regionally and providing opportunities for mutual sharing, learning, and benchmarking was crucial to reach a critical mass of champions and believers. 
Regional voices were important not just for sharing and learning but to validate global advocacy and policy. These same ministers, researchers, and practitioners from Africa and Asia brought commitments and demands to sessions at the Commission on the Status of Women in New York, the Water and Health Conference in North Carolina, International Women's Day, the World Health Assembly in Geneva, and other global platforms. They helped break the silence from the bottom up (George 2013; Patkar et al. 2017; WaterAid 2013; WSSCC and UN Women 2015b; WSSCC 2016a, 2016b, 2017a, 2017b; UNC 2017; Essity 2017b).

\section{Expanding the Conversation to Other 'Unmentionables'}

As ministers and senior bureaucrats, village chiefs, parliamentarians, and the media started openly discussing menstrual health and hygiene, would they also be more open to conversations on other hitherto taboo topics? In Senegal, Cameroon, and Niger, menstruators who talked about their first period went on to describe menstrual experiences across their lives (WSSCC and ONU Femmes 2015), including stories of genital cutting and injuries during childbirth (Mimche et al. 2017). These were taboo topics, shameful for perpetrators, accomplices, and victims alike, that commanded humble listening.

These conversations-across different countries and cultures and often initiated around health-seeking behaviors, child spacing, and contraception-provided a natural space to disrupt notions of voice, control, choice, and even gender identity and expression. Most important was the discussion around fertility, especially in countries in West Africa, where women themselves perceived that a woman's fecundity made them more attractive to men. Surrounded by myths, perceptions, and social stigma, women's information, support, and health-seeking behavior around menopause is not that different from menarche (Wambua 1997; see also Bacalja Perianes and Ndaferankhande [Chapter 33]; Dillaway [Chapter 21]; and Singh and Sivakami [Chapter 70] in this volume), as is the subject of female urinary incontinence (Aoki et al. 2017). The burden on individuals at these life stages is disproportionate to the limited attention in policy, research, financing, and care.

\section{Catering to the Diversity of Menstruators: Work in Progress}

Globally, menstruators suffer in silence, but many experience stigma and discrimination on multiple grounds: socioeconomic status, choice of occupation, gender identity, caste, class, ethnicity, and many other factors (see McCarthy and Lahiri-Dutt [Chapter 3]; Bozelko [Chapter 5]; Roberts [Chapter 6]; Vora [Chapter 4]; Sukumar [Chapter 13]; Steele and Goldblatt [Chapter 8]; Hawkey, Ussher, and Perz [Chapter 10]; Persdotter [Chapter 29]; Steward et al. [Chapter 55]; Frank and Dellaria [Chapter 7]; and Rydström [Chapter 68] in this volume). Disability, gender, and sexual identity were almost entirely absent from the emerging MHM conversation, as was the intersection of multiple stigmas throughout life, with particular vulnerabilities at puberty, pregnancy, childbirth, and menopause. 
The Sanitation Action Summit organized by WSSCC in Mumbai in November 2016 created a platform for listening, learning, and joint action (Sanitation Action Summit 2016). The summit brought together citizens from across India who are often silenced and/or made invisible - sanitation workers, adolescent girls and boys, transgender persons, older persons, and persons with hearing and/or visual impairments. It concluded: "The challenge is not just to build infrastructure like toilets but to fight stigma and prejudice that discriminate against women, girls, transgender persons, sanitation workers and many more" (WSSCC 2016b). The summit was followed by the publication of transformative national Guidelines on gender issues in sanitation (MDWS 2017), marking an important departure from narrow WASH messaging to explicit acknowledgment of the dangers of instrumentalist, stereotypical messages for behavior change. The guidelines state:

It is noted that behaviour-change messaging [in Swachh Bharat Mission (Gramin)] often includes subjects like 'shame and dignity of women.' While these may be useful for entry-point messaging they carry risks of lack of ownership by men and the reinforcing of gender stereotypes (like women should not step out of the house, men as custodians of women's dignity, etc.) The ... messaging should therefore be gender sensitive and targeted at both men and women, particularly focusing on men, who are often the primary decision makers in rural households where household expenditure is involved.

These guidelines are fairly radical in a culture that places women at two ends of a complex spectrum: the first, as the stereotypical goddess to be revered-a wife, daughter, or sister to be protected from the male gaze; and the second, a workhorse without agency. Significant in these guidelines is the emphasis on dignity versus patriarchal messaging that reinforces widely accepted perceptions of a woman's modesty, dignity, and therefore place in society (MDWS 2017). The guidelines go on to advocate for inclusion and adaptation to ensure that the third gender, ${ }^{12}$ elderly persons, children, and persons with disabilities have unfettered access to facilities. They end with detailed guidance to address MHM-related taboos and superstitions and specifically acknowledge women's sanitation stress and insecurity and call for better siting, ventilation, and consideration of age and disability in facilities design and management.

\section{Persons with Disabilities}

MHM poses particular challenges for persons with disabilities (Majumdar 2019). At the Sanitation Action Summit 2016, visually impaired girls talked about these struggles. One girl explained, "Since there are no dustbins or other disposal facilities, we are dependent on our relatives to throw away used pads" (WSSCC 2016c). Another girl added: "When there are no toilets we go out to change our sanitary materials. This is unsafe as we cannot see stray animals or 
other hazards" (WSSCC 2016c). Finally, yet another girl stated: "We are often pressured by our families to remove our uterus in order to stop menstruating" (WSSCC 2016c; see Steele and Goldblatt [Chapter 8] in this volume).

Through learning and innovation partnerships with the Centre of Excellence in Tactile Graphics of the Indian Institute of Technology and the Saksham Trust, our team ${ }^{13}$ published an MHM toolkit for persons with visual impairments (WSSCC 2018). This toolkit comprised a tactile book, facilitators manual, tactile apron, audiobook, EPUB, and a video in Indian Sign Language. Before publication, it was tested in Sri Lanka and India through five regional workshops for 250 trainers who work with persons with visual impairments. Of those trained, $30 \%$ subsequently used the materials with 4748 visually impaired girls (Newz Hook 2019). In February 2018, Minister Uma Bharati and Secretary Parameswaran Iyer, of India's Ministry of Drinking Water and Sanitation, launched the toolkit on MHM, which was endorsed by the Ministries of Social Welfare and Drinking Water Supply and Sanitation.

\section{Transgender Persons}

Nuanced policies and practice that address menstruators in all their diversity is a rare opportunity to embrace nonbinary definitions of identity and sexuality. The silence and taboo around periods is further exacerbated for trans men, who report stigma, discomfort, annoyance, disgust, and pain linked to menstrual periods (Bell 2019). Expanding the MHM work to the trans community met with opposition from WSSCC's Board in Geneva despite the huge demand in the country and the support of WSSCC's Executive Director. ${ }^{14}$ Early conversations and workshops with the trans community in South Asia, have uncovered persistent menstrual stigma among trans men (Sarfaraz 2016) underlining the value of a human, holistic approach to sexual reproductive health and rights, with menstruation as a powerful entry point to redefine ancient feminine and masculine boundaries.

\section{Essential Ingredients to Reach the Tipping Point}

Malcolm Gladwell described what he termed the 'tipping point' (2000) and identified three key variables for social epidemics: (1) The power of the few (a few individuals who are convinced and clear); (2) the stickiness factor (the change must make sense to people); and (3) the power of context (the change must be relevant to the context and culture). Gladwell's framework can be extrapolated to explain some of what worked in our efforts to transform the deafening silence around menstruation into language and action.

While the countries were different, the methodology was consistent: a deliberate recipe designed to produce an 'aha moment' of realization that menstruation is not 'dirty' or 'polluting,' but entirely natural. Women's and girls' voices and participation had to be matched with empathy, understanding, and action from duty bearers. Many MHM trainings and dialogues created a shared reality. 
The interaction, role plays, honest voices, and tough talk by many who had suffered ultimately produced changemakers, champions, movers, and shakers.

This journey revealed five key lessons:

1. Changes in social norms, institutions, and behaviors are best facilitated by simple, evidence-based policies anchored in voice and participation.

2. Men can be powerful, supportive agents of change when presented with a practical, action oriented, compelling arguments in the voices of those affected most.

3. Basic infrastructure, such as taps and toilets, by their sheer essential and ubiquitous, noncontroversial presence serve as powerful entry points to exploring and addressing gender issues and wider human rights at scale.

4. Human needs such as sanitation and hygiene-including those related to menstruation-are universal. But the services to address these basic needs are traditionally gendered, catering to a young, virile male. They ignore the life course and associated physical and psychosocial factors through which users perceive comfort, safety, convenience, and dignity. Acknowledging the diversity of changing needs in service delivery is transformative and quite doable.

5. Failing to do so will leave those who are currently unheard and often forgotten, even further behind.

I believe the changes in India, as well as in other countries, were more than just a response to an issue whose time had come. Rather, the evolution from stigma to openness about MHM brings together all the elements of Gladwell's framework. It was the result of sustained advocacy by a multitude of stakeholders with a belief in and commitment to change, an appetite for risk, and a long-term view; coupled with careful strategy, local champions, and systematic, multipronged interventions so that the seed takes root and grows into a dense forest. On reaching this tipping point, menstruation went from the silent unmentionable to being 'en vogue.'

\section{The Power of the Few}

The spokespersons in India in the 1990s who were instrumental in sowing the seeds of the dynamic field of menstrual health and hygiene were little-known movers and shakers, not Bollywood celebrities or UN officials. They understood very early the importance of matching advocacy with action to achieve change at scale. They were individuals and organizations who worked in this area, with no resources and no Internet to garner virtual support or share experiences. I must share a few as important sources of inspiration, courage, creativity, and leadership.

Santa Sheela Nair as the Principal Secretary of Municipal Administration and Water Supply in the Indian state of Tamil Nadu (2001) was one of the first to address the menstrual hygiene needs of women and girls in practice 
(Alok 2010). Known widely as India's water woman for her successful rainwater harvesting strategy that rescued the state from drought, she instituted a practical strategy to raise awareness and provide basic safe management and disposal options for schools in the state. A powerful and consistent advocate, she reminded global audiences at Rio+20 that women menstruate and menstrual hygiene is an inseparable aspect of WASH services.

Lakshmi Murthy founded Vikalp Design in 1988, focusing on sexual and reproductive health communication for rural adolescents. An early advocate for menstrual health, Lakshmi designed the Lace wallah kapda, a reusable cloth pad with straps, which evolved in 2000 into improved Uger pads (Murthy 2017). She developed simple tools-including the mahavari chakra, or menstrual wheel, later adapted by the WSSCC Yatra team-to teach young people about menstrual health (VikalpDesign 2005).

Anshu Gupta of Goonj developed the three pillars of awareness, access, and affordability to enable dignity during menstruation for millions of rural women (Murthy 2017). A pioneer in the quest for sustainable, planet-friendly menstrual products, Goonj's two-decade-old campaign, "It's not just a piece of cloth," has helped women bleed with dignity and safety while quietly providing an alternative to expensive and polluting menstrual products.

The Bangladesh Rural Advancement Committee (BRAC), one of the world's largest NGOs, boasted a sophisticated production and distribution system of affordable menstrual pads, produced locally by women as early as 2000 (Bharadwaj and Patkar 2004). In 2004, working with A. Mushtaque Chowdhury, Babar Kabir, and Milon Kanti Barua, on BRAC's gender strategy, I received encouragement to improve the integration and institutionalization of menstrual health into BRAC's program. Presented with women's very practical demands for materials, convenience, and privacy, BRAC management moved quickly to improve production and distribution of absorbents at an affordable price along with facilities redesigned to make menstruation a safe, comfortable, and dignified experience for women and girls.

\section{The Stickiness Factor}

Doing something about menstruation made sense to men and women of all ages and nationalities. WASH policies were universally focussed on infrastructure, so thinking about how menstruators would use facilities was a novel exercise. It made sense to policy makers and practitioners seeking to understand why women did not use facilities even when they existed (Winter et al. 2019), or why girls chose to stay away from school some days (Oster and Thornton 2011), and what menstruators actually did to cope. Most importantly it made sense to menstruators. It made sense to grandmothers and mothers who had been denied this simple information while growing up to see their charges glowing with new confidence. And it made sense to men and boys, who dispassionately considered this new information, reacting more often than not with empathy and support. 


\section{The Power of Context}

Yes, context is key and MHM advocates and practitioners adjusted programs, materials, and language to local realities. Yet, concerns of 'culture' and 'context' were submerged in the universality of biology, patriarchy, stigma, trauma, and coping strategies. Life is a lived experience with common threads and encounters across geographical, linguistic, sociocultural, and economic boundaries. While context shapes the unique experience of each menstruator, it is against a universal backdrop of stigma and restrictions, of ignorance of the human body and the reproductive cycle (see Chrisler 2013); of recurrent patterns restricting mobility, voice, and choice; and a ubiquitous external environment that denies a woman the right to participate fully alongside men in public life. The neglect of menstruators' needs was indeed universal. Local context nuanced the idioms and expressions, the restrictions placed at menarche, and the traditional practices in menstrual management, but the patterns were unmistakable and knew no geopolitical boundaries. Every time, in every context, the topic was relevant and long overdue. Each time, silence was replaced by stories of trauma and repression, quickly giving way to hope and ideas for change.

\section{Conclusion: What Lies Beyond the Tipping Point?}

These are early, heady days. Activists, entrepreneurs, and researchers are busy generating creative approaches, products, and evidence to bolster the case for menstrual health (USAID, Kiawah Trust, and Dasra 2014). This may be a good time to pause and take stock. There is no doubt that menstruation provides a powerful entry point to open up forbidden themes, questions, and perceptions and to renegotiate agreements on public goods and services. However, even when negotiated, owned, and published, normative frameworks must continue to be embedded in the voices that formed them to remain alive, relevant, and accountable. Otherwise they leave those who were central to the transformation far behind. Pragmatic solutions that translate policy into practice can move the dialogue on rights and entitlements at speed, yet, in the rush to reach scale, they risk losing the focus on voice and agency of the most marginalized.

Development policies, guidelines, and schemes tend to fit into two categories: (1) broad, sweeping statements of goodwill and change that are hard to implement and where no one is directly accountable, or (2) very specific guidelines that assign a budget and responsibility, often with tangible, measurable outcomes. The policy changes in India, Senegal, and Kenya fall into the second category. The subtext and wider frame around women's empowerment, however, did not fit neatly into subnational budget proposals and were not easily understood by finance ministries seeking visible accountability and tangible outcomes. Practitioners found it easier to mention the unmentionable and to distribute free menstrual pads than to ensure a holistic, 
transformative approach that included pride in one's body, knowledge of one's sexuality, and the information and freedom to make choices. The silence and taboo around menstruation was too easily replaced by gendered messaging on how women could manage their periods in line with a western image of the ultraconfident, modern woman who juggles a billion things, including her periods, effortlessly.

At the same time, human rights language is notoriously unpopular with governments in many countries, including in countries with active media and civil society networks. Opposition is based on a range of predictable reactions ranging from fear of public interest litigation to simple aversion to overtly feminist or transformative propositions that challenge 'how we do things here.' Even when human rights language is incorporated into policies, translating these far-reaching policies into practice is often elusive. Normative frameworks cannot be seen outside the sociocultural and economic contexts within which they are expected to bring about change. Those who engage in that context must tread carefully to be allowed to continue their work without shaking the status quo too much. For transformative change to take hold, only the voices of those most concerned can deepen the discourse and direct the winds of change.

Menstrual hygiene and health integrated into WASH and health policies have bordered heavily on practical needs, using binary definitions and largely 'safe' parameters. But they provide a stronger hook than well-meaning text on women's empowerment, impossible for finance and sector ministries to translate into action. Published policies are an important milestone and serve to direct the next steps in the journey. Without them, practice will continue to be eulogized as model villages or pilot projects, but defy scale. Generic language in policy around women's needs, suffering, and marginalization is unhelpful; it risks instant dilution in strategy and budgets, followed by business as usual at the implementation stage. It is important to spell out clearly stigmatized concepts, lay bare the reasons for stigma, and replace them with practical solutions that are universally acceptable. But that is just the beginning. Redesigned public spaces, open conversations at home across generations, and a new vocabulary spoken without fear bring confidence and new vistas. Menarche and menstruation symbolize much more than a monthly period to be managed: sexual and gender identity, desire, sense of self, voice, choices, womanhood, and rites of passage. They offer a powerful hook for the realization of multiple human rights.

\section{Notes}

1. Urmila Chanam, Krishna Ramawat, and Komal Ramdey in India.

2. Amita Sharma and Sumit Bose.

3. Tamsyn Barton, Peregrine Swann, Richard Montgomery, Alison Barret, Brian Baxendale, Nigel Kirby, and many others. 
4. Zelda Yanovich, David Trouba, Archana Patkar, WSSCC, Geneva with national coordinator Vinod Mishra and local consultants Vijay Gawade, Lakshmi Murthy, and Maria Fernandes.

5. Urmila Chanam, Vaishali Chandra, and Aneesha Menon (Volunteers from Arghyam), Krishna Ramawat (Goonj), and Maria Fernandes (Consultant, WSSCC).

6. The Swachh Bharat Mission or Clean India Mission, was launched by Prime Minister Modi for the period 2014-2019 with the aim of cleaning up the streets, roads, and infrastructure of India's cities, towns, and rural areas.

7. Rockaya Aidara and Archana Patkar, WSSCC.

8. Minister Mansour Faye, Amadou Diallo, Arouna Traore, Mingue Ndiatte Ndiaye, and many others.

9. Mbarou Gassama Mbaye, Dienaba Wane Ndiaye, Josephine Odera, Corinne Delphine N'daw.

10. Carol Koi, Abdiwahit Jama, Eva Muhia, Irene Gai, Christine Mwaka, Patricia Mulongo Neville Okwaro, Daniel Kurao, and Jane Kiminta in Kenya; Khady Sonko, Seynabou Sarr, Rokhaya Ngom, Khoudia Mbengue Fall in Senegal; Director, Labo Madougou in Niger; Beatrice Eyong, Jocelyne Alice Ngo Njiki, and Olivia Mvondo Boum in Cameroon.

11. Chaitali Chattopadhyay, Virginia Kamowa, and Archana Patkar.

12. In April 2014, the Supreme Court of India recognized hijras, transgender people, eunuchs, and intersex people as a 'third gender' in law. See National Legal Services Authority v Union of India, Writ Petition No. 400 of 2012 with Writ Petition No. 604 of 2013, Supreme Court of India (15 April 2014), available at: https://indiankanoon.org/doc/193543132/.

13. Kamini Prakash, Komal Ramdey, and Archana Patkar with Saksham and Noida Deaf Society. Publication by the Communications team, WSSCC Geneva.

14. Christopher Williams.

\section{REFERENCES}

Alok, Kumar. 2010. Squatting with Dignity: Lessons from India. New Delhi: Sage.

ANEW. 2013. "Opening of the WSSCC Training on Equity and Inclusion in Sanitation and Hygiene in Senegal." ANEW Africa, September 13. http://www. anewafrica.org/news/article_article_115.html.

Aoki, Yoshitaka, Heidi W. Brown, Linda Brubaker, Jean Nicolas Cornu, J. Oliver Daly, and Rufus Cartwright. 2017. "Urinary Incontinence in Women." Nature Review Disease Primers 3 (17097). https://doi.org/10.1038/nrdp.2017.42.

Bell, Jen. 2019. "What It's Like to Get Your Period When You're Trans." Clue, February 18. https://helloclue.com/articles/cycle-a-z/what-it's-like-to-get-yourperiod-when-you're-trans.

Bharadwaj, Sowmyaa, and Archana Patkar. 2004. "Menstrual Hygiene and Management in Developing Countries: Taking Stock." Junction Social, Social Development Consultants 3: 1-20.

Bobel, Chris. 2019. The Managed Body: Developing Girls and Menstrual Health in the Global South. Cham, Switzerland: Palgrave Macmillan.

Boyce, Paul, Sarah Brown, Sue Cavill, Sonalee Chaukekar, Beatrice Chisenga, Mamata Dash, Rohit K. Dasgupta, et al. 2018. "Transgender-Inclusive 
Sanitation: Insights from South Asia." Waterlines 37 (2): 102-17. https://doi. org/10.3362/1756-3488.18-00004.

Burt, Zachary, Kara Nelson, and Isha Ray. 2016. "Towards Gender Equality through Sanitation Access." UN Women. https://www.unwomen.org/en/digital-library/ publications /2016/3/towards-gender-equality-through-sanitation-access.

Chanam, Urmila. 2012. "The Nirmal Bharat Yatra-Goodwill on Wheels!" India Water Portal, November 11, 2018. https://www.indiawaterportal.org/articles/ nirmal-bharat-yatra-goodwill-wheels.

Chandra-Mouli, Venkatraman, and Sheila Vipul Patel. 2017. "Mapping the Knowledge and Understanding of Menarche, Menstrual Hygiene and Menstrual Health among Adolescent Girls in Low- and Middle-Income Countries." Reproductive Health 14 (30). https://doi.org/10.1186/s12978-017-0293-6.

Chandra Sharma, Neetu. 2018. "Use of Sanitary Pads Sparse Despite Govt Schemes: Studies." Live Mint, February 10. https://www.livemint.com/Politics/zbk4JLAnsoHjmbvplrgeNJ/Use-of-sanitary-pads-sparse-despite-govt-schemes-studies.html.

Chrisler, Joan. 2013. "Teaching Taboo Topics: Menstruation, Menopause, and the Psychology of Women." Psychology of Women Quarterly 37 (1): 128-32. https:// doi.org/10.1177/0361684312471326.

CREA. 2005. "Adolescent Sexual and Reproductive Health and Rights in India.” New Delhi: Creating Resources for Empowerment in Action (CREA). http://www. nipccd-earchive.wcd.nic.in/sites/default/files/PDF/18\%20adolescent $\% 20$ working\%20paper.pdf.

Desai, Priya. 2012. "The Nirmal Bharat Yatra (The Great WASH Yatra) - A Travelling Carnival Over 6 Weeks Spreading Awareness on Sanitation and Hygiene in India.” India Water Portal, September 24. https://www.indiawaterportal.org/articles/ nirmal-bharat-yatra-great-wash-yatra-travelling-carnival-over-6-weeks-spreadingawareness.

Essity. 2017a. "Joining Forces for Progress: Hygiene Matters Report 2016/17." http://reports.essity.com/2016-17/hygiene-matters-report/hygiene-matters-survey-2016-17.html.

Essity. 2017b. "Hygiene-A Circle of Life." https://www.essity.com/company/ essentials-initiative/stories-and-videos/hygiene-a-circle-of-life/quotes-aboutthe-initiative/.

Fernandez, Maria. 2012. "The Nirmal Bharat Great WASH Yatra: What a Long, Strange and Wonderful Journey It Has Been." Water Supply and Sanitation Collaborative Council. https://www.wsscc.org/2012/11/16/the-nirmal-bharatgreat-wash-yatra-what-a-long-strange-and-wonderful-journey-it-has-been/.

Geertz, Alexandra, Lakshmi Iyer, Perri Kasen, Francesca Mazzola, and Kyle Peterson. 2016. "Menstrual Health in Kenya: Country Landscape Analysis." FSG. https:// menstrualhygieneday.org/wp-content/uploads/2016/04/FSG-Menstrual-HealthLandscape_Kenya.pdf.

George, Rose. 2012. "When Neelam Started Her Period, She Thought She Was Dying Like Her Mother." New Statesman America, November 9. https://www. newstatesman.com/world-affairs/2012/11/when-neelam-started-her-periodshe-thought-she-was-dying-her-mother.

George, Rose. 2013. "Celebrating Womanhood: How Better Menstrual Hygiene Management Is the Path to Better Health, Dignity and Business." Geneva: Water Supply and Sanitation Collaborative Council. https://www.issuelab.org/ resources/19523/19523.pdf. 
Gottipati, Sruthi. 2012. "Vidya Balan and Jairam Ramesh Ream Up for Toilets." India Blogs-New York Times. September 29, 2012. https://india.blogs.nytimes. com/2012/09/29/vidya-balan-and-jairam-ramesh-team-up-for-toilets/.

Government of Kenya. 2019. "Cabinet Approves Policies to Stimulate Economic Growth, Empower the Youth.” November 21, 2019. https://www.president. go.ke/2019/11/21/cabinet-approves-policies-to-stimulate-economic-growth-empower-the-youth/.

Gupta, Aditi. 2013. "Practising Hygiene Is as Important as Performing Pujas." Menstrupedia, November 4. http://menstrupedia.com/blog/practising-hygiene-isas-important-as-performing-pujas- $2 /$.

Indian National Congress. 2018. "Nirmal Bharat Abhiyan: Everything You Need to Know about Nirmal Bharat Abhiyan." October 29. https://www.inc.in/en/in-focus/nirmal-bharat-abhiyan-everything-you-need-to-know-about-nirmal-bharat-abhiyan.

Kathmandu Declaration. 2013. "Sanitation for All: All for Sanitation." Fifth South Asian Conference on Sanitation, October 22-24. Kathmandu, Nepal. https:// sacosan.com/wp-content/uploads/2017/10/Fifth-SACOSAN-KhatmanduDeclaration-2013.pdf.

Kosgi, Srinivas, Vaishali N. Hegde, Satheesh Rao, Shrinivasa Bhat Undaru, and Nagesh B. Pai. 2011. "Women Reproductive Rights in India: Prospective Future." Online Journal of Health and Allies Sciences 10 (1): 1-5. http://ro.uow.edu.au/ medpapers/130.

Kulkarni, Seema, Sneha Bhat, Kathleen O'Reilly. 2017. "No Relief: Lived Experiences of Inadequate Sanitation Access of Poor Urban Women in India." Gender and Development 2: 167-83. https://doi.org/10.1080/13552074.2017.1331531.

Ma, Julie. 2016. "25 Famous Women on Periods." The Cut, October 21. https:// www.thecut.com/2016/10/25-famous-women-on-periods.html.

Majumdar, Swapna. 2019. "How a Tactile Book Helps Visually Impaired Women Deal with Their Period." The Hindu, March 16. https://www.thehindu.com/society/ how-a-tactile-book-helps-visually-impaired-women-deal-with-their-period/article26544937.ece.

Mimche, Pr Honoré, Seke Desyg, Maxime Tiembou Noumeni, Moïse Tamekem, Rockaya Aidara, and Mbarou Gassam Mbaye. 2017. "Menstrual Hygiene Management and Female Genital Mutilation: Case Studies in Senegal.” Water Supply and Sanitation Collaborative Council. https://www.wsscc.org/wp-content/ uploads/2018/01/20171227_Policy-GHM-Senegal-EN-WEB-1.pdf.

Ministère de l'Hydraulique et de l'Assainissement, République du Sénégal. 2016. "Lettre de Politique Sectorielle de Développement. 2016-2025." https://www. pseau.org/outils/ouvrages/mha_lettre_de_politique_sectorielle_de_developpement_2016_2025_2017.pdf.

Ministry of Drinking Water and Sanitation (MDWS). 2013. Office Memorandum. Government of India, No. SMG-1/2013-RDD (NBA), December 10. http:// hptsc.nic.in/M3.pdf.

- 2015. "Menstrual Hygiene Management: National Guidelines." December. Government of India. https://jalshakti-ddws.gov.in/sites/default/files/Menstrual $\% 20$ Hygiene\%20Management $\% 20-\% 20$ Guidelines.pdf.

- 2017. "Guidelines on Gender Issues in Sanitation." Government of India, No. S-11018/2/2017-SBM. March 4. https://jalshakti-mdws.gov.in/sites/default/ files/Guidelines\%20on\%20Gender\%20issues\%20in\%20Sanitation.pdf. 
2018. "Guidelines for Swachh Bharat Mission (Gramin)." December 31. Government of India. https://jalshakti-ddws.gov.in/sites/default/files/ SBM\%28G\%29_Guidelines.pdf.

Murthy, Lakshmi. 2017. "The Journey of Menstrual Hygiene Management in India. \#ThePadEffect." Feminism India, May 19. https://feminisminindia. com/2017/05/19/journey-menstrual-hygiene-management-india/.

Naafs, Arjen, and Tim Brewer. 2013. "Progress on SACOSAN v. Commitments." Traffic Lights Paper. Freshwater Action Network South Asia, WaterAid. http:// www.freshwateraction.net/sites/freshwateraction.net/files/Final\%20Traffic\%20 Lights\%20Paper\%202016.pdf.

Naeve, Katie, Julia Fischer-Mackey, Jyotsna Puri, Raag Bhatia, and Rosaine N. Yegbemey. 2017. "Evaluating Advocacy: An Exploration of Evidence and Tools to Understand What Works and Why." International Initiative for Impact Evaluation, Working Paper 29. https://doi.org/10.23846/wp0029.

Narayan, Ravi, Henk Van Norden, Louisa Gosling, and Archana Patkar. 2011. "Equity and Inclusion in Sanitation and Hygiene in South Asia." A Regional Synthesis Paper. UNICEF/WSSCC/WaterAid.

Newz Hook. 2019. "World Menstrual Hygiene Day-Tactile Kit Explains Periods to Visually Impaired Girls.” May 29. https://newzhook.com/story/21724.

Okwaro, Neville and Isobel Davis. 2017. "Master Training of Trainers on Menstrual Hygiene Management Nepal \& Pakistan.” WSSCC, Workshop Report, February 20-26. https://www.wsscc.org/wp-content/uploads/2017/04/Nepal-MHM-ToTReport-Final-2017.pdf.

Okwaro, Neville, Sailas Nyareza, Jenny Karlsen, and Inga Winkler. 2016. "First National Training of Trainers on Menstrual Hygiene Management-Kenya." Workshop Report. Water Supply and Sanitation Collaborative Council. https:// www.wsscc.org/wp-content/uploads/2016/08/Kenya-MHM-ToT-Report.pdf.

O'Reilly, Kathleen. 2016. "Surviving as an Unequal Community: WASH for Those on the Margins." In Eating, Drinking: Surviving the International Year of Global Understanding (IYGU), edited by Peter Jackson, Walter E. L. Spiess, and Farhana Sultana, 51-56. Cham: Springer.

Oster, Emily, and Rebecca Thornton. 2011. "Menstruation, Sanitary Products and School Attendance: Evidence from a Randomized Evaluation." American Economic Journal: Applied Economics 3 (1): 91-100. https://doi.org/10.1257/app.3.1.91.

Patkar, Archana. 2012. "Speech by Archana Patkar at the Nirmal Bharat Yatra Launch.” Water Supply and Sanitation Collaborative Council. https://www.wsscc. org/2012/10/01/speech-by-archana-patkar-at-the-nirmal-bharat-yatra-launch/.

- 2016. "Leave No One behind: Equality and Non-Discrimination in Sanitation and Hygiene." In Sustainable Sanitation for All, 267-80. Rugby, UK: Practical Action Publishing. https://doi.org/10.3362/9781780449272.016.

Patkar, Archana, and Emily Deschaine. 2014. "Translating Silence into ActionProgress on Policy and Practice in Menstrual Hygiene Management." In WASH in Schools Empowers Girls' Education: Proceedings of the Menstrual Hygiene Management in Schools Virtual Conference 2013. New York: United Nations Children's Fund and Columbia University.

Patkar, Archana, Rockaya Aidara, and Anthony Dedouche. 2017. "Water Sanitation and Hygiene in the Informal Sector: Case Studies from Africa and Asia." CSW61 
NY, Water Supply and Sanitation Collaborative Council. https://www.wsscc.org/ wp-content/uploads/2017/05/CSW61-Session-Summary-Feb17-1.pdf.

Phadke, Shilpa, Sameera Khan, and Shilpa Ranade. 2011. Why Loiter? Women and Risk on Mumbai Streets. New Delhi: Penguin Books India.

Prabhu, K. Seeta, Anita Rampal, and Alok Shukla. 1995. "The Madhya Pradesh Human Development Report." UNDP. https://www.undp.org/content/dam/ india/docs/human_development_report_madhya_pradesh_1995_full_report.pdf.

Puri, Jo. 2016. “Evaluating Advocacy-What Are We Learning?” Geneva: International Initiative for Impact Evaluation. https://genevaevaluationnetwork. files.wordpress.com/2015/05/advocacy_geneva_april_5_2016_3ie.pdf.

Sahoo, Krushna Chandra, Kristyna R. S. Hulland, Bethany A. Caruso, Rojalin Swain, Matthew C. Freeman, Pinaki Panigrahi, and Robert Dreibelbis. 2015. "Sanitation-Related Psychosocial Stress: A Grounded Theory Study of Women Across the Life-Course in Odisha, India." Social Science \& Medicine 139: 80-89. https://doi.org/10.1016/j.socscimed.2015.06.031.

Sarfaraz, Kainat. 2016. "Trans-Men: A Minority Within the Marginalised." Indian Express, December 10. https://indianexpress.com/article/india/transgendertransmen-third-gender-minority-rights-empowerment-4415111/.

Sikri, A. Supreme Court of India. National Legal Services Authority v Union of India, Writ Petition No. 400 of 2012 with Writ Petition No. 604 of 2013, Supreme Court of India. April 15, 2014. https://indiankanoon.org/doc/193543132/.

Singh, Manvi. 2019. "It's Time Teachers Stopped Skipping the Reproduction Chapter." Youth Ki Awaaz, May. https://www.youthkiawaaz.com/2019/05/ as-the-children-are-growing-shouldnt-sex-education-grow-with-them/.

Sixth South Asian Conference on Sanitation. 2016. "Better Sanitation Better Life." The Dhaka Declaration. https://www.endwaterpoverty.org/sites/default/files/ oldfiles/SACOSAN_VI_declaration.pdf.

Sommer, M., B. Caruso, M. Sahin, T. Calderon, S. Cavill, T. Mahon et al. 2016. “A Time for Global Action: Addressing Girls' Menstrual Hygiene Management Needs in Schools." PLoS Med 13 (2): e1001962. https://doi.org/10.1371/journal. pmed.1001962.

Theseira, Julian. 2016. "WSSCC Fulfils Its SACOSAN VI Commitments to Train Governments and Influencers in South and South-East Asia with 'MHM \& Gender in WASH' Training in Sri Lanka." Water Supply and Sanitation Collaborative Council. https://www.wsscc.org/2017/11/16/wsscc-fulfils-sacosan-vi-commitments-train-governments-influencers-south-south-east-asia-mhm-gender-washtraining-sri-lanka/.

Thirunavukarasu, A., and Doug Simkiss. 2013. "Developments in Reproductive Health Education in India." Journal of Tropical Pediatrics 59 (4): 255-57. https:// doi.org/10.1093/tropej/fmt066.

United Nations General Assembly Resolution 64/292. The Human Right to Water and Sanitation, A/Res/64/292, July 28, 2010. https://undocs.org/A/ RES/64/292.

United Nations General Assembly Resolution 70/165. The Human Rights to Safe Drinking Water and Sanitation, A/Res/70/169, December 17, 2015. https:// undocs.org/A/RES/70/169.

University of North Carolina. 2017. "Water and Health Conference: Where Science Meets Policy." https://waterinstitute.unc.edu/conferences/waterandhealth2017/. 
USAID, Kiawah Trust, and Dasra. 2014. "Spot On! Improving Menstrual Health and Hygiene in India." https://www.dasra.org/resource/improvingmenstrual-health-and-hygiene.

VikalpDesign. 2005. "Mahwari Chakka." https://www.vikalpdesign.com/mahwari_ chakka.html.

Wambua, L. T. 1997. “African Perceptions and Myths about Menopause.” East African Medical Journal 74 (10): 645-46. https://www.ncbi.nlm.nih.gov/pubmed/ 9529747.

WaterAid. 2013. "Making Connections: Women, Sanitation and Health.” April 29, 2013. https://sswm.info/sites/default/files/reference_attachments/Making_Connections_ Women_Sanitation_and_Health_290413.pdf.

WaterAid, WSSCC, and Unilever. 2013. "We Can't Wait: A Report on Sanitation and Hygiene for Women and Girls." https://www.unilever.com/Images/we-can-twait---a-report-on-sanitation-and-hygiene-for-women-and-girls--november-2013_ tcm244-425178_1_en.pdf.

Winkler, Inga T. 2016. “The Human Right to Sanitation.” University of Pennsylvania Journal of International Law 37: 1331-1406. https://scholarship.law.upenn.edu/ jil/vol37/iss4/5.

Winkler, Inga T., and Virginia Roaf. 2014. "Taking the Bloody Linen Out of the Closet-Menstrual Hygiene as a Priority for Achieving Gender Equality." Cardozo Journal of Law and Gender 21 (1): 1-37.

Winter, Samantha Cristine, Robert Dreibelbis, Millicent Ningoma Dzombo, and Francis Barchi. 2019. “A Mixed-Methods Study of Women's Sanitation Utilization in Informal Settlements in Kenya." Plos One. https://doi.org/10.1371/journal. pone.0214114.

WSSCC. 2013a. "Menstrual Hygiene Management: Training of Master Trainers." Water Supply and Sanitation Collaborative Council. https://www.wsscc.org/ wp-content/uploads/2016/04/WSSCC-MHM-India-Training-of-TrainersReport-New-Delhi-India-24-27-September-2013.pdf.

_. 2013b. "The Menstrual Wheel." Water Supply and Sanitation Collaborative Council. https://www.wsscc.org/resources-feed/menstrual-wheel/.

—. 2013c. "MHM Lab Convenor's Manual." WSCC Learning Series: Menstrual Health Management. Water Supply and Sanitation Collaborative Council. https:// www.wsscc.org/wp-content/uploads/2015/10/MHM-lab-manual-EN-LowRes.pdf.

- 2016a. "CSW60-Achieving Gender Equality through WASH-Event Programme." Water Supply and Sanitation Collaborative Council. https://www. wsscc.org/resources-feed/achieving-gender-equality-wash-event-programme/.

- 2016b. "Changing Hearts and Minds to Leave No One behind. Sanitation Action Summit 2016: Reflections." https://www.wsscc.org/wp-content/ uploads/2017/02/Sanitation-Action-Summit-2016-India.pdf.

- 2017a. "CSW61-Water Sanitation and Hygiene in the Informal Sector: Session Summary." Water Supply and Sanitation Collaborative Council. https:// www.wsscc.org/wp-content/uploads/2017/05/CSW61-Session-SummaryFeb17-1.pdf.

. 2017b. "Health and Hygiene Across the Life Course." World Health Assembly, Side Session Report. The Water Supply and Sanitation Collaborative Council, SCA, Government of Kenya and WaterAid. https://www.wsscc.org/ wp-content/uploads/2017/06/Health-and-Hygiene-Across-the-Life-CourseWHA-2017-Report-final.pdf. 
2018. "As We Grow Up: A Tactile Book on Menstrual Hygiene Management Facilitator's Manuel (EN and HIN)." Water Supply \& Sanitation Collaborative Council. https://www.wsscc.org/resources-feed/grow-tactile-bookmenstrual-hygiene-management-facilitators-manual/.

WSSCC and ONU Femmes. 2015. "Gestion de L'Hygiene Menstruelle: Comportements et Pratiques Dans la Region de Kedougou, Senegal.” https:// menstrualhygieneday.org/wp-content/uploads/2016/12/UN-Women-GHMComportements-et-Pratiques-K\%C3\%A9dougou-S\%C3\%A9n\%C3\%A9gal.pdf.

WSSCC and UN Women. 2015a. "Information Letter no. 5, April-June 2015." The Joint Programme on Gender, Hygiene and Sanitation, WSSCC/UN Women. https://www.wsscc.org/wp-content/uploads/2016/10/Info-letter-5-JointProgramme-on-Gender-Hygiene-and-Sanitation.pdf.

—. 2015b. "Information Letter No. 7, October-December 2015." The Joint Programme on Gender, Hygiene and Sanitation, WSSCC/UN Women. https:// www.wsscc.org/wp-content/uploads/2016/03/GHS_Info_Letter_7_EN.pdf.

- 2016. "Best Practices of the Joint Programme on Gender, Hygiene and Sanitation.” WSSCC/UN Women. https://www.wsscc.org/wp-content/ uploads/2016/11/Best-Practices-of-the-Joint-Programme-on-Gender-Hygieneand-Sanitation-UN-Women-WSSCC.pdf.

YouTube. 2012. "Jairam Ramesh and Vidya Balan Launch 'Nirmal Bharat Yatra."” https://www.youtube.com/watch?v=mUwKqj7gUFI\&feature=youtu.be.

Open Access This chapter is licensed under the terms of the Creative Commons Attribution 4.0 International License (http://creativecommons.org/licenses/ by $/ 4.0 /$ ), which permits use, sharing, adaptation, distribution and reproduction in any medium or format, as long as you give appropriate credit to the original author(s) and the source, provide a link to the Creative Commons license and indicate if changes were made.

The images or other third party material in this chapter are included in the chapter's Creative Commons license, unless indicated otherwise in a credit line to the material. If material is not included in the chapter's Creative Commons license and your intended use is not permitted by statutory regulation or exceeds the permitted use, you will need to obtain permission directly from the copyright holder.

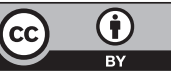

